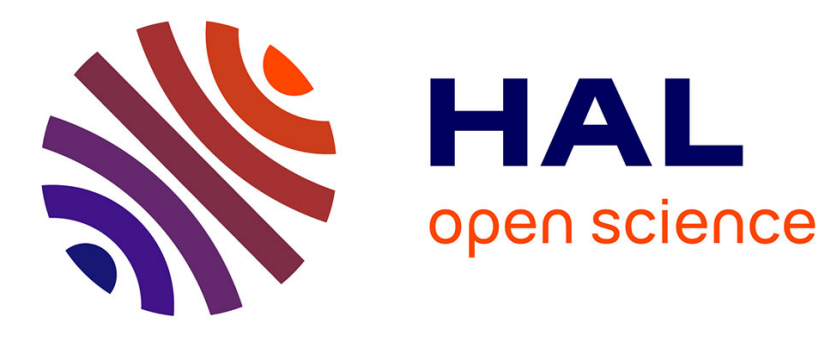

\title{
Spatial dynamics and urban models
}

Denise Pumain

\section{To cite this version:}

Denise Pumain. Spatial dynamics and urban models. J. Hauer, H.Timmermans and N. Wrigley. Urban dynamics and spatial choice behaviour, Springer, pp.155-173, 1987, 978-94-010-6944-1. 10.1007/97894-009-1009-6_8. halshs-01625416

\section{HAL Id: halshs-01625416 https://shs.hal.science/halshs-01625416}

Submitted on 27 Oct 2017

HAL is a multi-disciplinary open access archive for the deposit and dissemination of scientific research documents, whether they are published or not. The documents may come from teaching and research institutions in France or abroad, or from public or private research centers.
L'archive ouverte pluridisciplinaire HAL, est destinée au dépôt et à la diffusion de documents scientifiques de niveau recherche, publiés ou non, émanant des établissements d'enseignement et de recherche français ou étrangers, des laboratoires publics ou privés. 


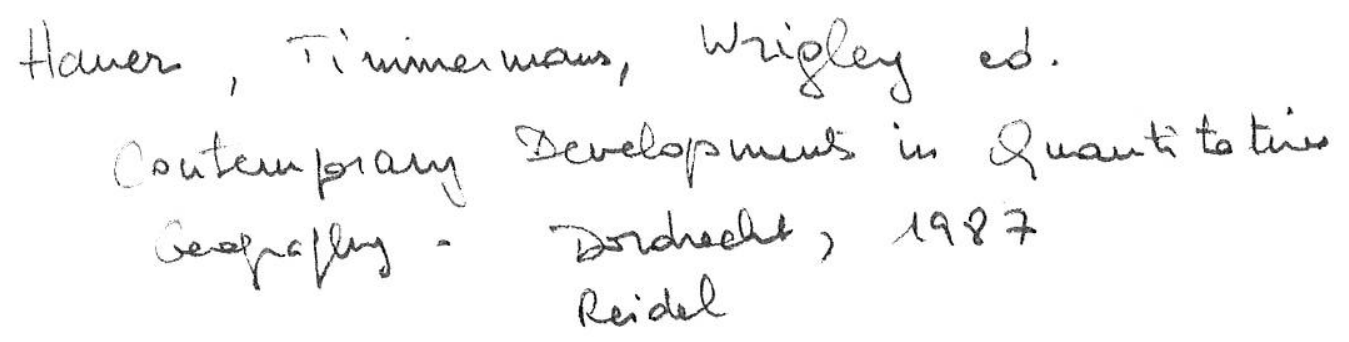

Denise PUMAIN

SPATIAL DYNAMICS AND URBAN MODELS

\section{THE SELF-ORGANIZATION IDEAS: NEW WINE OR NEW BOTTLES ?}

Analogies and model transfer from one branch of research to another are often fruitful. They allow new progresses in knowledge by using already elaborated formalisms or models and by arising new associated questions which may lead to new fields of research. But they do not avoid the two opposite risks : one is to be contented by a vague and empty analogy which is in fact nothing but a new discourse; the other is to lay on an ill-adapted methodology which distorts too much the subject under study.

\subsection{Characteristics of self-organizing systems}

One aim in designing dynamic models in geography is to understand and anticipate the evolution of socio-spatial systems. New dynamic models mainly refer to analogies in physics, for instance chemical kinetics (ALLEN, 1978) or laser theory (HAAG, WEIDLICH, 1984). The systems in study are described at least at two levels : system-wide (macroscopic variables) and elementary (microscopic level). There is a very large number of elements in the system. Sometimes a third level of description is added, with subsystems comprising variable numbers of elements. Differential equations describe the variation of a macroscopic variable with time. They are obtained after definitions of interactions at the microscopic level, between the elements of the system. The passage from the microscopic level to the macroscopic description of the system is the more arduous problem in such a frodelisation and may lead to stochastic formulations, when interactions between the elements do not have a deterministic form but when their results are known only as probability distributions. According to physical theories as the "dissipative structures theory", phenomena of self-organization and of bifurcation may occur in open systems when they are maintained under 
an influx of energy. Those systems may organize themselves in structures which are created or destroyed during the evolution of the system. This evolution is both deterministic, according to a trajectory which can be predicted after the equations of a model describing interdependencies between variables ; and random, or undetermined, during periods of instability when a change in structure (or a phase transition) can occur. The equations of the model may therefore admit several solutions or multiple equilibria, several possible trajectories corresponding to qualitatively different structures, between which the system may be driven towards one branch or another, towards a given form of organization, by the amplification of a small fluctuation (after PRIGOGINE, 1979 and ALLEN, SANGLIER, 1981).

Many sources of instability are intervening in the evolution of such open systems when they are situated far from equilibrium. On one hand they continually undergo internal fluctuations, variations in the level of their characteristic variables (which may result from changes in the micro-states of the elements of the system) ; on the other hand, they are always subject to external perturbations stemming from their environment. An open system is then continually adjusting the level of its variables or the size of its subsystems and maintain a relative structural persistence only when this structure constitutes, under the given conditions, a stable state for the system, that is a state towards which the system come back after having gone a little apart of it. The structure is then viewed as an attractor on the system's trajectory. The dynamical instability may induce a passage from one trajectory to another, from one structure to another structure, that is from a given qualitative behaviour of the system to another, through a bifurcation point.

This kind of modelization provides then tools for analyzing the systems dynamics in connection with the following questions : - is there any equilibrium state ? are there many? (the reference here is to a dynamic equilibrium, that is a stable structure, a qualitative behaviour of the system having a certain persistence);

- what is the kind of the equilibrium states : stationnary, unstable, periodical ?

- what is the consequence of a modification in the values of the parameters of the model upon the evolution of the system and upon its possible equilibrium states ?

\subsection{Grounds for analogy}

To what extent does it appear useful to develop an analogy between such physical systems and the systems which are usually studied by geographers ?

When formalizing a geographical object in this framework 
as a dynamic spatial system, one has to define it as a set of elements, which are either located elements or geographical zones ; location (at least relative location) must appear as a basic property of the elements of the system ; the interactions between those elements must be at least partly spatial interactions, which are linked to expressions of the absolute (site) or relative (situation) location of the elements ; the state of the system is defined as the geographical configuration of its characteristic variables. A geographical structure is then given by a particular relative size and evolution for the state variables and/or located subsystems which are used for the description of the geographical system.

At the most disaggregated level, a spatial system can be formalized as a set of localized and interacting actors (individuals or groups as persons, households, firms, associations...) who are using and continu-ously re-creating geographical differences and spatial configurations. These interactions are various in nature and form : competition for space, propensity to agglomerate, segregative tendencies, imitation... According to the case, they generate the homogeneity or the diversity of contents, the increase or the decrease in gradients, the concentration or the dispersal in distributions. One has to hypothesize that the dynamics of these interactions is creating the spatial structures, for which they are together an expression and their condition for existence.

Such a formalization has many appealing features for geographers :

- it allows to stress the linkages between the individual behaviour of the actors and interactions defined at this microscopic level on the one hand, and the macroscopic descriptors of the system on the other hand. Many researches have been conducted and empirical regularities established for each scale of study separately, without always a clear connection between those two levels of observation. Here, self-organisation phenomena, meso- or macro- scale structures, are described as consequences of an interaction game between individuals, each animated by their own objectives. These consequences are not always intuitive to the observator, they are often not concerted and even most of the time not perceived by the actors. - This approach may also give an interpretative framework for observed regularities in spatial systems. The instability of elements being considered (1), it is only because bifurcations occur in the evolution of dynamic systems, because their trajectory "jump" from one attractor to another that identifiable and separable categories, or large-scale regularities, may be observed. Temporal series appear then as "possible" 
sequences of complex dynamics, and very often the problem for social sciences, where experimentation is impossible, consists in finding which was the dynamics which produced a particular temporal serie of observable structures, a specific trajectory (PRIGOGINE, 1979). In geography, according to R. BRUNET (1980), the number of simple spatial structures (which he calls : "chorèmes") is reducible to some forty. They could be considered as a serie of attractors among the set of all theoretically imaginable trajectories representing the evolutions of spatial configurations, where random fluctuations are occurring. - Another interesting feature of this approach is that the historical dimension of social systems is taken into account with the concept of irreversibility. On the one hand, the explanation of the state of a system at a given date integrates necessarily its passed trajectory, its history. The contemporary structure includes the "memory" of previous bifurcations. On the other hand, the caracteristic fluctuations of dynamic systems imply that it is impossible to prepare initial conditions which would lead to identical futures. The impossibility of exact prediction is then given as a theoretical "a priori". However, the analysis of the dynamic behaviour of the systems and of their sensitivity to changes in parameter values allows the exploration of a limited number of possible futures, according to the hypotheses made upon the evolution of the parameters (ALLEN, SANGLIER, 1981).

Those ideas may appear seductive for geographers. But it is not because of their novelty : all of them have been enonciated a long time ago. It is because they allow to relax some of the more oppressive restrictions imposed by the previous ways of modelization and because new experimental tools related to these old ideas are henceforth available.

(1) We have showned elsewhere (PUMAIN, SAINT-JULIEN, SANDERS, 1986) examples of instability in the evolution of the elements belonging to urban systems. 


\section{SOME DIRECTIONS IN URBAN AND REGIONAL MODELLING}

Instead of trying to present a complete review of existing models, which would never be exhaustive and soon become obsolete, I would like to recall some examples (2). They illustrate the variety of approaches which are used in that kind of modelization. I will not consider here the models where spatial interaction is not explicity taken into account : many applications in geography try to explain discontinuities in the temporal evolution of some size-variables measured on distinct spatial units (cities or regions). They may use several places to estimate the values of the parameters but they do not incorporate the effects of spatial competition in the construction of a spatial structure.

At least in human geography, most of the available examples happen to be found in fields where rather stable, general and well-known spatial structures can be observed and for which well-developed and efficient descriptive and sometimes predictive models already existed :

- intra-urban or interregional migration flows ;

- intra-urban distribution of population densities and land prices or rents;

- intra-urban distribution of residential population and service activities (extensions of the Garin-Lowry types of models) ; - inter-urban distribution of population sizes and functional hierarchical levels (development of central places networks).

As on the other hand very few applications of these new dynamic models to real-world data have been attempted until now, it is still difficult to give them as much credit for their empirical usefulness than for their potential theoretical value.

It has been showned that, when using non-linear equations and/or interdependencies between constituting variables, even very simple mathematical models could produce very complicated dynamics (MAY, 1976). Some of the models which are proposed to geographers are even too complex to be tractable analytically and must be solved and calibrated by the means of simulations. Another way of classifying dynamic models of spatial structures is then to consider how they choose between the advantages of complexity, allowing possibly more realistic representations and also more complete descriptions of spatial features, and the gain in generality and soundness of results offered by the existence of more or less well-known analytical solutions.

(2) References to other examples are given in the bibliography at the end of the paper. 


\section{1. "Simple" models}

In these models, formulations in use are more or less directly drawn on findings in other fields : catastrophe theory in mathematics, models of interacting species in biology like the Volterra-Lotka's ones, and the master-equation technique from physics. All those models can be solved analytically. It means that one knows how to identify the equilibrium states of the system, how many they are, if they are stable or not. One is then able to situate the observed trajectory in respect to these equilibria and to make predictions about the stability of the structure according to hypothetic variations in the values of parameters.

\subsubsection{Catastrophe theory}

Direct applications of R. THOM'S (1974) catastrophe theory to the study of spatial structures seem to must be limited. Despite this theory provides very good analytical tools ans theorems about the number and precise qualitative shape of the functions linking the state-variables for the elementary catastrophes, it allows then a too small number of variables and parameters to describe the system (respectively a maximum of two and four), so that it cannot be of great help in most of geographical problems. LUNG (1984) underlines the difficulties in constructing models which satisfy the basic assumptions of the theory : how to define a potential function, how to incorporate a competition for space, and how to find relevant state variables which may undergo sudden changes and induce another qualitative structure for smooth variations in the values of parameters.

Most of the studies in that field are still exploratory. A good review is given by WILSON (1981). Usually the spatial structure is strongly summarized by a global measure of size, or density, or intensity of spatial interaction, whose variations are related to a few control parameters. For instance, AMSON (1975) considers urban density as a state variable, which is depending upon two parameters : it is proportional to rental and inversely proportional to "opulence", which is a measure of the benefit from urban interaction. He shows that the density follows variations according to the fold model if a saturation effect is introduced, with rental becoming a logistic function of density. If a minimal threshold of available space per person is then added, the model for the variations of the density becomes a cusp. The condition for a smooth and continuous 
behaviour of the density is that one of the parameters, rental or opulence, will keep high values.

Catastrophe theory is used by many authors to describe discontinuities in urban growth. For example, MEES (1975) gives an interpretation of the revival of cities in Europe between 11th and 13th century, which followed a long period of urban decline, as a discontinuity in the relationship between the urbanization rate and the possibility of external trade. This discontinuity appears for a critical value in the decreasing transportation prices. A more comprehensive model involving a butterfly catastrophe takes as a state variable the population working in manufacturing in towns, which is a function of four control variables : density of regional population, average productivity, urban-rural productivity differential and difficulty of transport. Papageorgiou (1980) tries to explain the cases of sudden urban growth observed in 19 th or 20 th century by the existence of scale economies in the utility function of cities for the individuals : the technological changes, even increasing the utility in a continuous manner, may at a given level introduce a discontinuity in the urbanization rate, which is jumping from one equilibrium point to another, according to a fold catastrophe.

A third approach consists in explaining the existence of thresholds and hierarchical levels in urban systems by jumps and hysteresis phenomena of the catastrophe theory. So CASTI and SWAIN (1975) suggest that the functional level of a central place may be seen as a cusp function of two control variables : population and per capita income, whereas WILSON (1981) relates the size of various urban facilities or of urban centers to the benefits of facility size and to the disbenefits of travel. If the first control variable is a logistic function of size and the second a linear one, the size may vary with the slope of this last function according to a kind of fold catastrophe.

The most interesting feature of this family of models seems then that they provide good theoretical insights in the discontinuous behaviour of some aggregate variables. But they are still of little help in the modelling of spatial structure or spatial interaction.

2.1.2. Volterra-Lotka's model. This formulation depicts the evolution of the number of individuals belonging to two interacting biological species. Each species is also characterized by a birth-death process of the logistic type. Transposals of this formulation to geographical analysis have been tempted for instance by DENDRINOS and MULLALY (1981), but 
without a true spatial dynamics : in their urban model, variables taken instead of species are the city's population and its mean per capita income ; the model simulates the evolution of the share of an SMSA's population in the total national population $\mathrm{x}$ and of its relative level of per capita income $\dot{y}$. So the spatial interaction is not easily included in that kind of modelization. Equations of the model are of the following form :

$$
\begin{aligned}
& \frac{d x}{d t}=a(x(y-1)-\beta x) \\
& \frac{d y}{d t}=y \gamma(\bar{x}-x)
\end{aligned}
$$

where $\bar{x}$ is a carrying capacity of the SMSA, $a$ and $\gamma$ are speeds of adjustment and $B$ a coefficient of "urban friction". This model was choosen because it allows to replicate one of the most frequent behaviour among the 90 SMSA of United States observed by the authors between 1940 and 1977, which is of the sink-spiral type, with oscillations around successive equilibria. However, the scarcity of available data does not allow a strong empirical support to this model (figure 1).

Spatial interaction is not easily included in that kind of modelization : it appears only in a weak and implicit manner, since the size of one element in the system is expressed by a relative measure, as a share of the total sizes of the elements of the system. The same way of solving the spatial disaggregation's problem has been used for a dynamic model of regional development (DENDRINOS, 1984) describing "interaction" between population and income of nine regions of the United States. In such application, analogy with the original model is by no means clear and moreover the meaning of some of the parameters used in the equations is not well precised.

2.1.3. Master-equation approach. This statistical technique relies upon theoretical principles used in the field of synergetics. It could be of great interest to geographers, because it links explicitly the state transition probabilities of individuals, at a micro-level and the evolution of some variables describing a macroscopic structure. The master equation gives the variation in time of the probability of the possible configurations in the space of the state-variables. This probability of transition from one configuration to another depends on the hypothesis made upon the number and the 
nature of parameters affecting the individual transition probabilities. This stochastic formulation is then used to derive a deterministic equation for the evolution of the mean values, which allows the estimation of the parameters.

This procedure has been used for deriving a two-populations-two zones model of the Volterra-Lotka type (HAAG, in GRIFFITH and LEA, 1984). The migration rate of each population group from one zone to another depends on its preference for a given part of the city, of its propensity to cluster ("internal sympathy") and to join members of the other group (external sympathy"), and of a general mobility level (flexibility). The authors explore analytically all possible types of spatial configuration and levels of urban segregation according to the sets of values taken by those four parameters. In this simple version, such a model is a good pedagogic presentation of an elementary spatial dynamics.

The master equation approach has also been used for reformulating any intra-urban model of residential rent and density interactions (HAAG and DENDRINOS, 1983) with an application to twelve SMSA of the United States (DENDRINOS, HAAG, 1984). The SMSA are divided into two parts : the city center, and the suburbs. Utility functions depending on rent and density - levels through land availability are used to describe the individual behaviour of typical land-buyers (who move) and sellers (who transfer rental value from one zone to another). Aggregation of those individual behaviours produces a stochastic master equation, whose deterministic mean value describes the evolution of the population share and of the relative rent price in the central part of the urban unit. From simulations with empirical data, the authors predict a probable reversal in the suburbanization trend for the 1990's, if the parameters values which are standing for common general conditions of SMSA's environment dis not change over time.

A model of migration for a whole set of regions has been constructed under the same approach (HAAG, WEIDLICH, 1984). Individual transition probabilities from one spatial subdivision to another are defined as functions of the difference in utility of regions. They are aggregated to define an equation of movement of the probability of states of the system (e.g. : all possible configurations of pupulation repartition among regions), whose mean values equation is used for the estimation of parameters. The dynamics of the spatial system is then related to trend parameters whose values may be compared from one system to another, or over time(global mobility rate, "cooperation", that is an agglomeration effect, and a saturation effect, )and to a set of preferences for each region. The socio-economic variables which could explain these preferences are not included in the dynamic model. But, when fitted with a regression model upon a temporal serie of regional preferences as established from the model (after for instanze ancual migration tables), they allow to a certain extent a prevision of future migrations and of the further evolution of the regional spatial structure. 
An interest of this approach is certainly to give a clear relationship between the spatial behaviour of individuals and the global dynamics of a spatial structure as measured by aggregated variables. All parameters, being diefined at the microlevel, receive a straightforward interpretation. This is always the case in models dealing only with state variables for the whole system.

\section{2. "Simple-complex" models}

One could consider in this category the models of the "Leeds' school" elaborated under A. WïLSON's direction. They are mainly models of intra-urban strurture, concerning the location of astivities and populations and the interaction flows that they generate. As information about those models is developed else whiere, I will only emphasize the interest of this approach : it is related to the types of modeling previously quoted in that sense that analytical solutions are explored, at least for the more genəral formulations of the models (WILSON, 1981, BEAUMONT et al., 1781). But it is always referring to a spatial structure (allowing a large number of zones in consideration) and attempt to modelize the interdependencies between the supply-side and the demand-side in the spatial dynamics. The aim is to produce an integrated model of urban structure, with relevant desaggregation of populations and activities and a connexion with determinants of individual behaviour.

The basic equations of those models stemm from the simple interaction model :

$$
F_{i j}=\frac{P_{i} W_{j}^{\alpha} e^{-\beta c i j}}{\sum_{j} W_{j}^{\alpha} e^{-\beta c i j}}
$$

where the flow $F_{i j}$ between a zone of residence $i$ and a zone of distination $j$ whère a service is offered diepends on $\mathrm{Wj}_{\mathrm{j}}$, a measure of attractivity of zone $j$ for this service, Pi being the number of residents in zone $i, \alpha$ is a parameter of sensitivity to scale economies for consumers, and $\beta$ a measure of their sensitivity to travel costs. In the dynamic varsions of the model the supply variable $W_{j}$ is diatermined endogenoissly as it adjusts itself to the total demand in each zone $D_{j}=\sum_{i} F i j$ :

$$
\frac{d W j}{d t}=\varepsilon(D j-k W j)
$$

where $\varepsilon$ is a speed of adjustment. 
According to the values of the parameters, bifurcations may occur in. the determination of the size and number of service centers. Such bifurcations and equilibrium points may be studied analytically for variations of one parameter, the other being hold constant (see figure 2) bist the global dynamics of the system can only be examined by the means of simulations.

An analogous form is retained for a second model, connected with the previous one, which locates the resident population in the city after the location of basic employment.

Disaggregated versions considering various income group, types of housing and kind of economic activities have been studied theoretically but not yet applied to empirical urban evolutions.

\subsection{Complex models}

Models of the Brussel's school are undoubtedly the more complex ones. They mainly deal with central-places development (ALLEN, SANGLIER, 1979) interregional shifts in population and tertiary employment (with one application at the state-level in United States : ALLEN, ENGELEN, 1984 and one at the province-level in Netherlands : ALLEN et al. 1985) and to intra-urban redistribution in labour force and residential population (ALLEN et al. 1981), with an application to the Brussel's region (ALLEN et al. 1984). In those models, the connexion with well-known mathematical processes is less clear and the equations can not be solved analytically. The spatial interactions are modelized mainly by the mean of attractivity functions, which characterize the advantages of one location in comparison of all other possible locations for each variable of the system. The mathematical expression of such attractivity functions is very complex and the dynamic behaviour of the variables can be studied only by the means of simulation. But in these equations are integrated a very large number of the theoretical proposals which where formulated to explain the dynamic of geographical structures. For instance, in the intra-urban model, mathematical relations or parameters stand for : multiplier mechanisms of the economic base, spatial interactions according to an intervening opportunities-type, growth upon limited space according to a logistic curve, mechanisms of competition for space and of social segregation, inequal speed of reaction and more or less large similarity in behaviour according to the information available to the urban actors. 
That kind of model provides then a useful tool to test the effects of these processes when acting all simultaneously in the evolution of a spatial structure. They allow to observe the evolution of the system in a global way, which is in a sense nearer of real-world conditions than in the case of other types of modelization. But when using this very complex models for applications, one has to be very confident in their quality of representation, in their selection of relevant descriptors as well as for the meaning of the parameters that they include. Some of the specific problems associated to the use of dynamic models of complex spatial structures will then be next precised.

\section{PROBLEMS IN APPLYING COMPLEX DYNAMIC MODELS OF SPATIAL STRUCTURE.}

The following remarks rely mainly on an experimental use of P. ALLEN's INTRA-URBAN model to study the evolution of four french agglomerations (PUMAIN, SANDERS, SAINT-JULIEN, 1985), but many of them have aløo been formulated by others, for instance by experimentators of a WILSON's model on the case of Rome (LOMBARDO, RABINO, 1983). Having in mind the complexity of those dynamic models, these tentative applications to real-world situations could seem a premature exercise. They hold a plurality of difficulties, because they use mathematical devices, whose behaviour is still not well-known, and because they call upon numerous and not always readily available data.

Large urban models have suffered from many criticisms. But nowadays stress is placed on qualitative features of spatial urban development more that on pure growth aspects. The ability of dynamic models to simulate such qualitative changes is one of their chances of success. However, it may be a valuable way to improve the design of future models, by underlying the main difficulties encountered in their applications. Problems are of various nature, being either conceptual or more practical.

\section{1 Conceptual problems}

The objectives of such applications usually follow three stages : first is to check that the model is a good description of the kind of system under study; second is to test that the model is able to replicate an observed evolution of a particular system; third is to assess that it may under given assumptions lead to a few plausible predicted trajectories for the future of the system. The imprecisions which may arise when borrowing concepts from another field have then to be clarified. For instance, when taken theoretically, the use 
of the bifurcation concept looks rather simple : one slight change in a value of a parameter can drive the system on another trajectory with a different kind of spatial configuration, it is a structural change. But when using those models for practical purposes, we are facing the reverse problem : observing a qualitative change in spatial configuration, we may wonder if it corresponds to a bifurcation : would one slight modification in one parameter value have been sufficient to avoid it, or to make it else, in this region of instability ? or is this change more deeply tied to the functioning of the system ? In that case, it would be naturally produced by the same trajectory defined by the non-linear equations and the corresponding set of values for the parameters has to be estimated. So, observing the evolution of an urban structure, we face the question of discovering a plausible dynamic path which may have generated it. But to what extent is it trustable enough to support prevision?

As a practical illustration one may recall two different kinds of interpretations, which have been proposed to explain the reversal in migratory flows between the core and periphery of urban areas which appeared recently in most industrialized countries : 1) a " clean break with the past ", a discontinuity or even the end of the urbanization process; 2) a part of a cyclical behaviour as regarding the agglomeration and dispersion tendencies, due to continuous variations in the values of parameters like income, transportation easiness or average spatial needs. In both cases, alternative trajectories which could be constructed in order to illustrate the bifurcation would not be the same.

This most irritating and fascinating aspect of transfering concepts in the end rejoins the classical problem of model specification and selection of variables - which in turn is closely tied for applications to the problem of the availability of data.

\subsection{Data problems}

They are not specific to this kind of modelization but are of decisive importance in the effective quality of applications. The scarcity of localized temporal statistical series at a detailed geographical level is well-known, even for aggregate variables. For instance, when testing his model of urban development, DENDRINOS (1981) disposed only of three points in time to check the possible interaction between urban income and population (fig. 1). For models needing information at a microlevel, the lack of data is even worse, as surveys establishing conditional probabilities in spatial behaviour are still too rare. 
The lack of empirical knowledge about the relevant range of values for the parameters of the models is another worrying problem; for instance in applying the intra-urban model, we could not find for french cities any published estimations of parameters which were however very often referred to, such as propensity of activities to agglomerate, differential sensitivity of populations to the length of commuting, intensity of segregative tendencies between social groups, induction rates between service employment and resident population, agglomeration economies, speed of adjustment of entrepreneurs to the demand ... All these values had to be estimated by the mean of calibration of the observed evolution of employment and resident population in the communes of the four french agglomerations being studied. Dynamic modeling could contribute to improve this situation by helping to select the parameters which are decisive in the construction of spatial structures and then to incite the development of the corresponding measurements.

\subsection{Calibration problems}

Considering the extreme complexity of this kind of model and its high sensitivity to small variations in parameters, the calibrating operations, trying to reproduce by simulation an observed evolution, are always long and difficult. The usual calibrating automatic procedures, even when designed for a large number of simultaneously varying parameters, are ineffective : because of bifurcation properties of such systems, many sets of parameters values may give local optima for the criteria which evaluates the global deviation between observed and simulated evolution. The values of the parameters have then to be determined by a trial and error method. This type of calibration is arduous and costly, since the effect of one slight variation in the value of one parameter may differ according to the configuration of values for the other parameters : each time a bifurcation occurs, the calibration process has to come back to a previous stage.

The evaluation of a goodness-of-fit, sufficient to decide to stop the calibration process, is not straight away either. As usual in geographical modeling, there is a contradiction between the hypothesis that general processes are valuable for all spatial units, and the lack of precision in estimation due to specific local conditions. For instance in P. ALLEN's intraurban model, as besides in WILSON's model, the city is represented as an open system where internal interactions determine the urban structure, starting from initial conditions which incorporate the whole history of the system. A more or less implicit assumption is that these interactions operate in the 
context of a liberal economy, where adjustments between supply and demand and a relatively free competition for space are the main mechanisms governing the urban dynamics. Now, the few applications which have been made for instance for P. ALLEN's model have shown that the calibration was more difficult and that the residuals between observed and simulated evolutions were larger when planning operations had been into effect. It was the case for Netherlands regions when large housing programs had been developed (ALLEN et al., 1984) and in large french agglomerations for communes where large building zones for social housing had been designed. One come then to the paradoxical situation (known as the "polder paradox"), that the more previous planning has been efficient, and the less the model can operate, therefore the better you planned the less you can predict a future evolution ...

\subsection{Interpretation problems}

In most of the applications already mentioned, it seems that the models were able to reproduce the large variety of changes as observed in most of the spatial units and that the largest residuals between simulated and observed evolution reflected spécific local conditions which were not taken into account by the model. In other words, the general mechanisms put in the model seem to describe rather well the evolution of urban structure.

But a problem remains with the interpretation of the values calibrated for the parameters. Those estimated values are not independent of the number of spatial divisions being considered, neither of the size of these zones and of the measurement unit of the variables. It is almost impossible to consider of arriving to a standardization of the parameters. For instance, in order to avoid the inequalities in areas of administrative urban units for which data are collected, one may think of converting absolute numbers of jobs and residents of P. ALLEN's model to densities. But the theoretical considerations which are included in the specification of the model are actually related to quantities. Anyway, the general logistic form of the equations renders parameters values dependent of the absolute numbers which express the size order of variables.

One has then to consider that the parameters values resulting of an operation of calibration reflect together the actual dynamics of the system and the way it has been disaggregated. When constructing or applying such types of dynamic models, a special attention must then be given to the disaggregation problem : the design of spatial units, the selection of 
the state variables at the micro and macro levels, according to the range of their spatial action and also to the time-scale of their intervention - if they have a fast or a slow dynamics.

Those considerations are of particular importance when such models are used for comparative studies. If the parameters of the models cannot be standardized, procedures allowing to compare complex dynamics of spatial structures have to be elaborated. For instance, in the case of urban models where spatial dynamics is created by differential values in the attractivity functions, one may compute ratios between values taken by those functions for two different sub-areas. In our application of P. ALLEN's model (PUMAIN et al., 1985) ratios between the highest and second highest values for each component of the attractivity functions were used to compare the intensity of agglomerative tendencies in four urban agglomerations, where concentration of activities in the center was a permanent but inequally evolving feature of the spatial structure. By comparing attractivity ratios for spatial units which were either contiguous or separated by a given distance, one was able to measure differentials in the effects of accessibility upon the development of service activities in respect to the location of resident population in the four agglomerations. Those are only examples of what has to be done if such models are to be used in a more operational context. If the objective is not only to make a qualitative exploration of various possible spatial configurations under given rules of individual behaviour, but if it is also to get a deeper insight in the evolution of urban structures where no spectacular bifurcation occurs, one has still to improve the experimental use of dynamic models.

\section{CONCLUSION}

This paper has focussed interest on dynamic models which try to explain the evolution of spatial structures at a meso or macro-level from interactions operating between the elements of the system. Of course, this can only lead to a certain level of explanation. It can throw an interesting light on such systems where the dynamics of elementary spatial interactions produces a morphogenesis, a spatial structure as observed at an upper level, the properties of which were not intended by the elements. For instance, the intentions of the individual actors are not from the beginning to produce an urban system, with a given spatial organization (but when it exists they use it and may try to improve some of its properties).

This particular level of understanding will also be of greater interest if many systems of different types appear to 
show the same kind of dynamic behaviour, if, as P. WINTWARTER (1984) has suggested, some "isodynamics" (a word forged like "isomorphisms") can be observed. Much work has still to be done in linking spatial properties of individual behaviour, interaction processes and the resulting spatial configurations, as expressions of a limited number of typical dynamics.

Bifurcation models in the urban field seem for the moment better designed for a theoretical or even pedagogical understanding of the qualitative features of urban structures and of their development than for operational uses. Even if they are still difficult, mainly because of data problems, applications have to be emphasized for a better evaluation of the practical interest of each type of models. One should particularly compare applications to the same urban case of models with different specifications. 
ALLEN (P.) 1978 : Dynamique des centres urbains. Sciences et Techniques, avril, $\mathrm{n}^{\circ} 50$, pp. $15-19$.

ALLEN (P.) SANGLIER (M.) 1978 : Dynamic models of urban growth. Journal of Social and Biological Structures, $\mathbf{n}^{\circ} 1$, pp. $265-280$ and $1979,{ }^{\circ} 2$, pp. 269-298.

ALLEN (P.) SANGLIER (M.) 1979 : A dynamic model of growth in a Central place system. Geographical Analysis, vol. $11, \mathrm{a}^{\circ} 3$, Pp. 256-272.

ALLEN (P.) SANGLIER (M.) 1981 : Urban evolution, self organization and decisionmaking. Environment and Planning, vol. 13, pp. 169-183.

ALLEN (P.) SANGLIER (M.) BOON (F.) DENEUBOURG (J.L.) DE PALMA (A.) 1981: Models of urban settlement and structure as dynamic self-organizing system. Washington, D.C., Department of Transportation.

ALLEN (P.) ENGELEN (G.) 1984 : Modélisation de l'évolution des Etats-Unis 1950-1970, in : Guermond ed. : L'analyse de système en géographie. Lyon, PUL, P. 257-277.

ALLEN (P.) ENGELEN (G.) SANGLIER (M.) 1984 : Computer Handled Efficency Stimuli Explo ration. Final Report, Noord Holland, Contract for Provinciaal Bureau Energiebesparing, $68 \mathrm{p}$.

ALLEN (P.) ENGELEN (G.) SANGLIER (M.) 1984 : Self-organizing systems and the laws of socio-economic geography. Brussels working papers on spatial analysis, série $A, \mathrm{n}^{\circ} 4,49 \mathrm{p}$.

AMORAL (Groupe) 1984 : La dynamique de système, une méthode de modélisation des unités spatiales. L'Espace Gêographique, $n^{\circ} 2$, pp. $81-93$.

AMSON (J.C.) 1975 : Catastrophe theory : a contribution to the study of urban systems Environment and Planning B, vol. 2, pp. 175-221.

BATTY (M.) 1976 : Urban modelling. Cambridge, Cambridge University Press.

BATTY (M.) KARMESHU 1983 : A strategy for generating and testing model 8 of migration and urban growth. Regional Studies, vol. $17, n^{\circ} 4$, Pp. 223-236.

BATTY (M.) HUTCHINSON (B.) eds, 1983 : Systems analysis in urban policy-making and planning. Oxford, Plenum Press, 619 p.

BEAUMONT (J.R.) CLARKE (M.) WILSON (A.G.) 1981 : The dynamics of urban spatial structure : some exploratory results using difference equations and bifurcation theory. Environment and Planning, A, $\mathbf{n}^{\circ} 13$.

BEAUMONT (J.R.) CLARKE (M.) WILSON (A.G.) 1981 : Changing energy parameters and the evolution of urban spatial structure. Regional Science and Urban Economics, 11, pp. 87-315.

BENNEIT (R.J.) HAINING (R.P.) WILSON (A.G.) 1985 : Spatial structure, spatial interaction, and their integration: a review of alternative models. Enviromert and Planning A, vol. 19, PP. 625-645.

BERTUGLIA (C.S.) OCELII (S.) RABINO (G.) TADEI (R.) 1980 : A model of urban structure and development of Turin : Theostical aspects. Sistemi Urbani, vol. I Pp. $59-90$. 
BERTUGLIA (C.S.) OCELLI (S.) RABINO (G.) SALOMONE (C.) TADEI (R.) 1983 : The dynamics of Turin metropolitan area; a model for the analysis of the processes and for the policy evaluation. Poitiers, Colloque europerer de l'Association de Sciences Régionales, 21 p. multig.

BRUNET (R.) 1980 : La composition des modeles dans l'analyse spatiale. L'Espace Géographique, $\mathrm{a}^{\circ} 4$, pp. 253-264.

BUSSIERE (R.) STOVALl (T.) 1981 : Systèmes évolutifs urbains et régionaux à l'état d'équilibre. Paris, C.R.U., 298 p.

CLARE (M.) WILSON (A.G.) 1983 a : The dynamics of urban spatial structure : progress and problems. Journal of Regional Science, vol. $13, n^{\circ} 1$

CLARK (M.) WILSON (A.G.) 1983 b : Exploring the dyanics of urban housing structure : a 56 parameter residential location and housing model. Poitiers, Congrès Européen de l'Association des Sciences Régionales.

COUCLELIS (H.) 1985 : Cellular worlds : a framework for modeling micro-macro dynamics. Environat and Planning A, vol. 17, pp. 585-596.

DENDRINOS (D.S.) 1980 : A basic model of urban dynamics expressed as a set of volterra Lotka equation, in Catastrophe Theory in Urban and Transport Analysi Washington D.C., Department of Transportation.

DENDRINOS (D.S.) MLLALY (H.) 1981 : Evolutionary patterns of urban populations. Geographical Analysis, vol. 13, n० 4, pp. 328-344.

DENDRINOS (D.S.) 1984 : The structural stability of the US regions : evidence and theoretical underpinnings. Environment and Planning A, vol. 16, Pp. $1433-1443$.

DENDRINOS (D.S.) HAAG (G.) 1984 : Toward a stochastic dynamical theory of location : empirical evidence. Geographical Analysis, vol. $16, \mathrm{n}^{\circ} 4$, Pp. $287-30$

DOMANSKI (R.) WIERZBICKI (A.P.) 1983 : Self organization in dynamic settlement systems. Papers and Proceedings of the Regional Science Association, vol. 53, pp. $141-160$.

ERNST (I.) 1978 : Formalisation du processus d'urbanisation : une application de la théorie des catastrophes. Cahiers de la SEMA, $\mathrm{n}^{\circ} 2$, pp. 75-90.

FORRESIER (J.W.) 1969 : Urban Dynamics. Cambridge (Mass.) M. I.T. Press.

FOURNIER (S.) 1983 : Dynamic of the urban growth of a french average size-city : the CARPE model, in Waterloo (Ontario) "New Directions in Urban Modelling".

GRIFFITH (D.A.) and MACK KINNON (R.) ed. 1981 : Dynamic spatial models. Alphen aan den Rijn, Sijthoff and Nordhoff, Netherlands.

GRIFFITH (D.A.) and LEA (A.C.) ed. 1984 : Evolving geographical structures, NATO Advan ced Institute Series. Den Hag, Martinus Nijhoff.

GUERYOND (Y.) ed. 1984 : Analyse de système en géographie. Presses Universitaires de Lyon. 
HAAG (G.) DENDRINOS (D.S.) 1983 : Toward a stochastic dynamical theory of location: a nonlinear migration process. Geographical Analysis, vol. $15, n^{\circ} 3$ Pp. 269-286

HAAG (G.) WEIDLICH (W.) 1984 : A stochastic theory of interregional migration. Geographical Analysis, vol. 16, $\mathrm{n}^{\circ} 4$, pp. 331-357.

ISARD (W.) LIOSSATOS (P.) 1979 : Spatial dynamics and optimal space-time development. New York, North-Holland, 434 p.

LOMBARDO (S.) RABINO (G.) 1983 : Non linear dynamic models for spatial interaction : the result of some empirical experiment. Poitiers, Congrès Européen de 1 'Association de Science Régionale.

MEES (A.I.) 1975 : The revival of cities in medieval Europe. An application of catastrophe theory. Regional Science and Urban Economic, vol. 5, pp. 403-425.

PAELINCK (J.) 1980 : Dynamic Urban Growth models. Papers of the Regional Science Association, vol. XXIV, PP. 25-37.

PESCHEL (M.) MENDE (W.) 1983 : Leben wir in ein Volterra welt ? Berlin, Akademie Verlag

PRED (A.) 1984 : Place as historically contingent process : structuration and the Time-Geography of Becoming Places. Annals of the Association of American Geographers, 74 (2), pp. 279-297.

PRIGOGINE (I.) STENGERS (I.) 1979 : La nouvelle alliance. Paris, Gallimard.

PUMAIN (D.) 1982 : La dynamique des villes. Paris. Economica.

PUMAIN (D.) SAINT-JULIEN (T.) 1978 : Les dimensions du changement urbain. Paris, C.N.R.S., Mémoires et Documents de Géographie, 202 p.

PUMAIN (D.) SAINT-JULIEN (Th.) SANDERS (L.) 1983 : Dynamics of spatial structure in french urban agglomerations. Papers of the Regional Science Association.

PUMAIN (D.) SAINT-JULIEN (T.) SANDERS (L.) 1984 : Vers une modélisation de la dynamique intra-urbaine. L'Espace Géographique, $\mathrm{n}^{\circ} 2$, pp. $125-135$.

PUMAIN (D.) SAINT-JULIEN (T.) SANDERS (L.) 1986 : Urban dynamics of some french cities. European Journal of Operational Research, vol. $25, n^{\circ} 1,3-10$.

PUMAIN (D.) SANDERS (L.) SAENT-JULIEN (T.) 1985 : Dynamique des systèmes et milieu urbain. Paris CNRS, rapport pour le PIREN, $197 \mathrm{p}$.

PUU (T.) 1981 : Catastrophic Structural Change in a Continuous Regional Model. Regional Science and Urban Economics, 11, p. 317-333.

RECHENMANN (F.) 1982 : La dynamique des systèmes et son double. Rouen, stage CNRS "techniques mathématiques pour l'analyse de système en géographie".

REYMOND (H.) 1981 : Une problématique théorique de la gẻographie : plaidoyer pour une chorotaxie expérimentale, in : Problématique de la géographie, Paris, PUF, pp. 163-262. 
REYMOND (H.) 1981 : L'ouverture informatique en géographie urbaine : de l'analyse multivariée socio-économique à la simulation organique des systèmes urbains. Informatique et Sciences Humaines, $n^{\circ} 50, p p .9-20$.

ROEHNER (B.) 1983 : Contribution à l'étude des processus stocastiques de naissance et mort : aspects théoriques et application. Université de Paris IV thèse de doctorat d'Etat.

ROEHNER (B.) WIESE (K.), 1982 : A Dynamic Generalization of Zipf's Rank-Size Rule. Environment and Planning A, 14, p. 1449-1467.

SANDERS (L.) 1984 : Interaction spatiale et modalisation dynamique, application aux systèmes urbains. Université Paris VII, thẻse de 3ème cycle.

SHEPPARD (E.) 1985 : Urban system population dynamics : incorporating non linearities Geographical Analysis, $\mathrm{n}^{\circ} 1$, pp. 47-73.

THOM (R.) 1974 : Modelles mathématiques de la morphogénèse, nouvelle éd. Paris, Christian Bourgeois, 1980, 315 p.

WAGSTAF (J.M.) 1977 : A possible interpretation of settlement pattern development in terms of "catastrophe theory". Transaction, Institute of British Geographers, $\mathrm{n}^{\circ}$ 3, Pp. $165-178$.

WEGENER (M.) 1983 : A simulation study of movement in the Dortmund housing market. Tijdschrift voor Econ. en Soc. Geografie, 74, $n^{\circ} 4$, Pp. 267-281.

WHITE (R.W.) 1977 : Dyaamical central place theory. Geographical Analysis, 9, pp. 226 243.

WHITE (R.W.) 1978 : The simulation of central place dynamics : two sector systems and the rank size rule. Geographical Analysis, 10, p. 201-208.

WHITE (R.W.) 1983 : Chaotic behaviour and the self-organization of urban retail syste Brussels working papers on spatial analysis, série $A, n^{\circ} 3,33 \mathrm{p}$.

WILSON (A.G.) 1981 : Catastrophe theory and bifurcation : applications to urban and regional system. London, Croom Helm, $331 \mathrm{p}$.

WILSON (A.G.) 1984 : Kaking urban models more realistic : some strategies for future research. Environment and Planning, vol. 16, pp. 1419-1432.

WINIWARTER (P.) 1984 : Iso-dynamics of population-size distribution in hierarchical systems. Los Angeles, Society for General Systems Research, annual meeting. 
Figure 1 Simulation of an urban evolution by a model of the Volterra-Lotka type

(after Dendrinos and Mullaly, 1980)

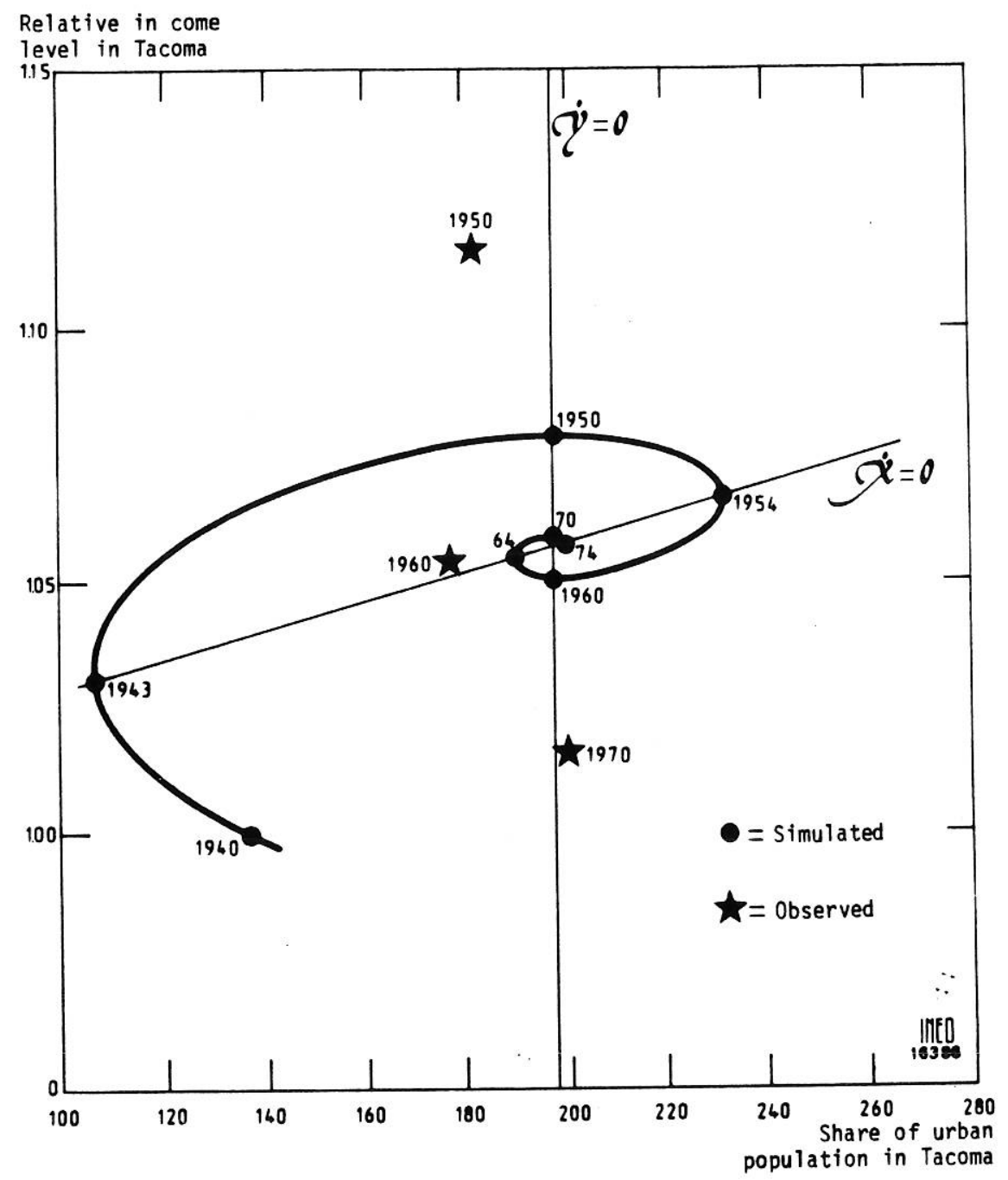


Figure 2 Bifurcations in the development of services centers

(after Wilson, 1981)
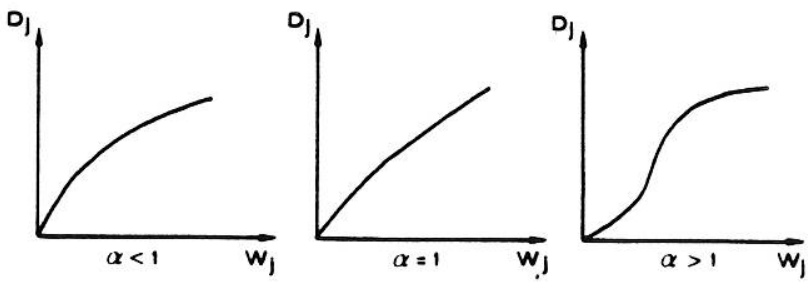

i- Effect of the taste of consumers as regarding
the size of centres (a) on the relationship
between supply $(\mathrm{Wj})$ and demand $(\mathrm{Dj})$ of services
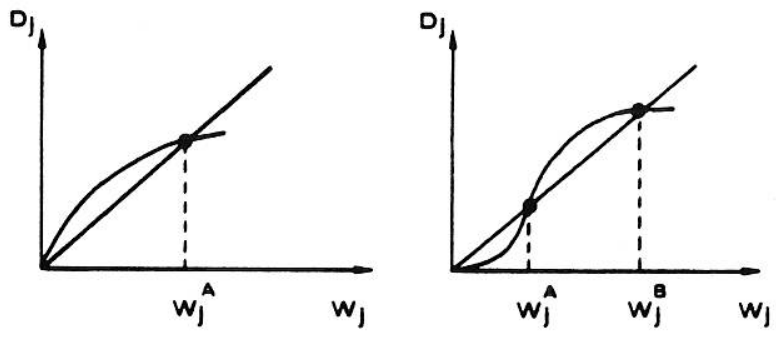

$\alpha<1$

$\alpha>1$

ii- Points of stable (B) and instable (A) equilibria between supply $(\mathrm{Wj})$ and demand $(\mathrm{Dj})$ for services

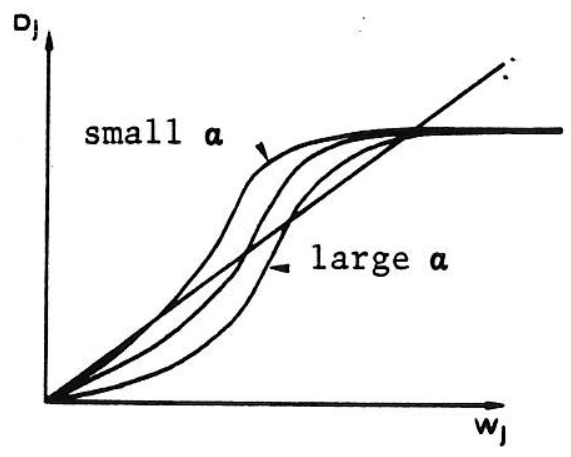

iii- Effect of the taste of consumers as regarding the size of centres (a) on size thresholds 
Since a few years geographers have become more and more involved in the construction of spatial dynamic models. Three main reasons could explain such a marked interest : first, the large diffusion from other disciplines of the "systemic paradigm" as an integrating framework and as a relevant heuristic tool ; second, the use of mathematic models which were first drawn up for theories in physics, chemistry or biology and were made suitable for the description of self-organization phenomena in any open system ; third, the incorporation of locational properties and spatial interactions in the equations of such dynamic models. I would like to stress some of the reasons which may explain why this new field of research seems so conceptually appealing for geographers. Some of the main leading tendencies for such modelling will then be reviewed in the domain of urban and regional geography. A set of problems encountered when using non-1inear complex dynamic models will then be mentioned in the case of tentative applications to empirical data. However, the existing litterature is already too large and there are to many varieties of approaches for pretending to present something else than a rather superficial introduction to the subject. 